\title{
Using pedotransfer functions to estimate soil hydraulic conductivity in the Loess Plateau of China
}

\author{
Chunlei Zhao ${ }^{\mathrm{a}, \mathrm{c}}$, Ming'an Shao ${ }^{\mathrm{a}, \mathrm{b}, *}$, Xiaoxu Jia ${ }^{\mathrm{b}, *}$, Mubasher Nasir ${ }^{\mathrm{a}}$, Chencheng Zhang ${ }^{\mathrm{c}}$ \\ ${ }^{a}$ College of Natural Resources and Environment, Northwest AEF University, Yangling 712100, China \\ ${ }^{\mathrm{b}}$ Key Laboratory of Ecosystem Network Observation and Modeling, Institute of Geographical Sciences and Natural Resources Research, Chinese Academy of Sciences, Beijing 100101, China \\ c State Key Laboratory of Soil Erosion and Dryland Farming on the Loess Plateau, Northwest AGF University, Yangling 712100, China
}

\section{A R T I C L E I N F O}

\section{Article history:}

Received 11 December 2015

Received in revised form 15 March 2016

Accepted 30 March 2016

Available online 8 April 2016

\section{Keywords:}

Saturated soil hydraulic conductivity

Loess Plateau

Artificial neural network

Multiple linear regression

Stability

\begin{abstract}
A B S T R A C T
Soil hydraulic conductivity $\left(K_{s}\right)$ is a crucial soil physical property that not only influences soil hydrological processes, but also the planning for vegetation recovery, irrigation practice and drainage design. However, $K_{s}$ data are often lacking at large-scale soil database due to difficulties in direct measurement that is often labour intensive, time consuming and cost inefficient. The objective of this study was to compare the performance of different emerging methods [Multiple linear regression (MLR) and artificial neural network (ANN)] of $K_{s}$ prediction. The pedotransfer function (PTF) is one such method that is based on selected factors closely correlated with $K_{s}$ at regional scale. We collected disturbed and undisturbed soil samples in the 0-40 cm soil layer at 243 sites across the entire typical Loess Plateau of China $\left(430,000 \mathrm{~km}^{2}\right)$ and then measured $K_{s}$ and the potentially related factors. The results showed that $K_{s}$ was normally distributed with moderate a spatial variation ( $\left.\mathrm{CV}=67 \%\right)$. Correlation analysis indicated that bulk density (BD), saturated soil water content (SSWC), clay content (Clay), silt content (Silt) and latitude were closely correlated $(p<0.05)$ with $K_{s}$. Although the accuracies of MLR and ANN were equal in terms of estimating $K_{s}$, the stability of PTF developed via ANN was not as good as that of MLR. Thus PTF developed via MLR, which included BD, Silt and Clay, was considered as the best model for estimating $K_{s}$. There is a need to closely monitor the stability and repeatability of PTF during comparison and determination of PTF.
\end{abstract}

(c) 2016 Elsevier B.V. All rights reserved.

\section{Introduction}

Saturated soil hydraulic conductivity $\left(K_{s}\right)$ is an essential parameter for soil and water management problems related to ecology, agriculture and the environment (Yao et al., 2015). It is indispensable in the assessment of the processes of infiltration, irrigation and drainage (Aimrun et al., 2004). $K_{s}$ is one of the most sensitive input parameters for distributed hydrological models (Wang et al., 2013b). $K_{s}$ is also widely applied in simulating heat and mass transport in top soils and in describing and predicting water and solute transports in the soil (Cornelis et al., 2001).

Although there is major advancement in direct determination techniques of $K_{s}$, such techniques are still labour intensive, time consuming and cost inefficient, especially for larger scale applications (Saxton and Rawls, 2006). In addition, direct determination of $K_{s}$ at $200 \mathrm{~cm}$ soil depth or more are usually impracticable. As a result, there is hardly readily available $K_{s}$ data to meet simulation demands. Furthermore, there is the need to evaluate the potential effects of regional water cycle and solute transport in deep soils like in the Loess Plateau of

\footnotetext{
* Corresponding authors at: Key Laboratory of Ecosystem Network Observation and Modeling, Institute of Geographical Sciences and Natural Resources Research, Chinese Academy of Sciences, Beijing 100101, China.

E-mail addresses: shaoma@igsnrr.ac.cn (M.' Shao), jiaxx@igsnrr.ac.cn (X. Jia).
}

China (Wang et al., 2013a), Southern Australia (Robinson et al., 2006) and Eastern Amazonia (Nepstad et al., 1994).

As an alternative, pedotransfer function (PTF), which uses predictive functions and soil survey data to determine $K_{s}$ is widely accepted in soil science and engineering community (Duan et al., 2012; Minasny and Mcbratney, 2000; Yao et al., 2015; Chapuis, 2012). PTF is a good tool for assessing desired accuracy and reliability of specific applications (Wösten et al., 2001). Generally, soil hydraulic properties are influenced by the combined effects of soil parent materials, vegetation, topography and time (Brantley, 2008). All these factors potentially affect $K_{s}$ by influencing soil porosity and pore size distribution. Studies have shown that the systematic variation in $K_{s}$ is mainly explained by soil texture and porosity (Cosby et al., 1984; Pachepsky and Rawls, 1999; Rawls et al., 1993). Other studies have demonstrated the relevance of soil organic carbon (SOC) and bulk density (BD) in the prediction of $K_{s}$ (Wösten et al., 1999). Yet other studies have concluded that soil hydraulic properties like saturated moisture, field capacity (Saxton et al., 1986; Pachepsky and Rawls, 1999) and soil organic matter are important in predicting Ks (Wösten et al., 1999).

The development of PTF has greatly facilitated a widespread application of models to simulate water movement and solute transport in the field and at larger scales. In practice, data generated using PTF is not easily transferable to other bioclimatic zones (Mcbratney et al., 2002; Vos 


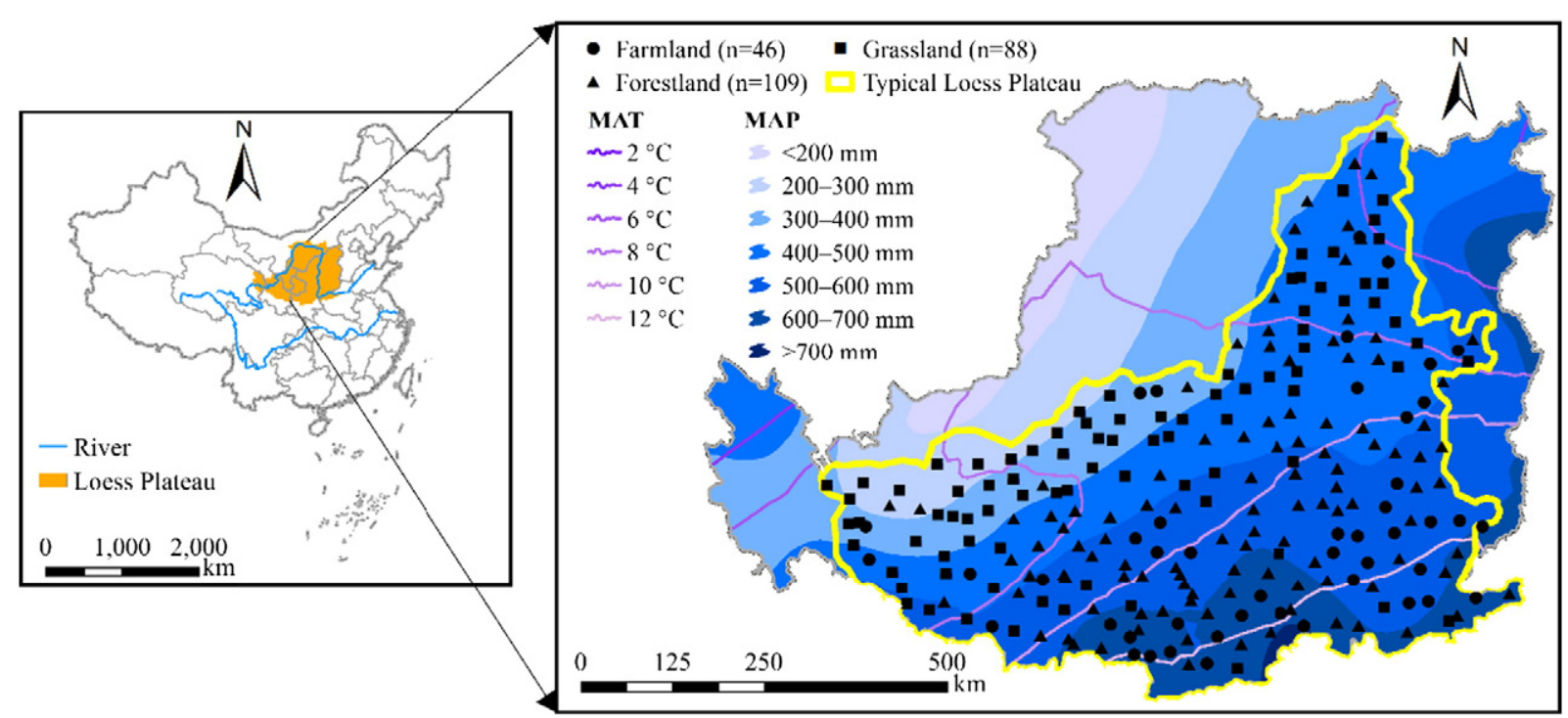

Fig. 1. Map depicting the 243 sampling sites along with the distribution of mean annual temperature (MAT) and precipitation (MAP) across the Loess Plateau in China.

et al., 2005). As climate influences the development of soil structure, it has adverse effect on PTF applied outside the region of design (Lilly et al., 2008). Therefore, it is important to make direct local measurements to develop PTF for regions where $K_{s}$ model has not been applied before.

The Loess Plateau of China (about $62 \times 10^{4} \mathrm{~km}^{2}$ ) has thick loess deposits, intensely soil erosion, severe water shortage and fragile ecosystem (Chen et al., 2007; Wang et al., 2008b). Soil moisture in the region comes mainly from natural recharge from limited precipitation, $55-78 \%$ of which falls in June to September. The hydrological processes directly affect vegetation rehabilitation and soil water conservation, a major issue of concern in the Loess Plateau for a several decades now. However, studies in the region have largely focused on spatial-temporal variability of $K_{s}$ (Hu et al., 2012; Zhou et al., 2009; Wang et al., 2013b; Lei et al., 2012), with even fewer studies emphasizing $K_{s}$ simulation (Zhao et al., 2014).

$K_{s}$ studies in recent decades were focused on relatively small spatial scales (generally $<2 \mathrm{~km}^{2}$ ), virtually insufficient for understanding largescale hydrological processes. There is therefore the need for information about large-scale prediction of $K_{s}$ and reliable PTF to more completely understand hydrological processes in the Loess Plateau region. Also recent developments in digital soil mapping and large-scale modelling emphasize the need for reliable PTF (Vereecken et al., 2010).

The objectives of this study were to: (1) characterize regional-scale variations in $K_{s}$ across the Loess Plateau; (2) determine the primary factors controlling regional distribution of $K_{s}$; and (3) develop a reliable and stable PTF for the estimation of $K_{s}$ in the Loess Plateau region.

\section{Materials and methods}

\subsection{Description of study area}

This study was conducted in a typical Loess Plateau (Yang et al., $1988)$ that covers about $2 / 3 \mathrm{rd}\left(43 \times 10^{4} \mathrm{~km}^{2}\right)$ of the Loess Plateau region $\left(34-45^{\circ} 5^{\prime} \mathrm{N}, 101-114^{\circ} 33^{\prime} \mathrm{E}\right)$. The typical Loess Plateau region is a spatial zone between the provinces of Shanxi, Shaanxi, Gansu, Ningxia, Henan and Inner Mongolia, where the loess is thickest (30-80 m) and most continuous with severe erosion and geomorphic landforms (Jia et al., 2015). It is located at an elevation of 200-300 m a.s.l. with "yuans" (large flat surfaces with little or no erosion), ridges, hills and gullies as the main geomorphic landforms. Mean annual precipitation (MAP) ranges from $150 \mathrm{~mm}$ in the northwest with a mean annual temperature (MAT) of $3.6{ }^{\circ} \mathrm{C}$ to $800 \mathrm{~mm}$ in the southeast with an annual mean temperature of $14.3^{\circ} \mathrm{C}$ (Fig. 1). The general transformation of the vegetation zone from the southeast to northwest is from the forest to forest-steppe to typical-steppe to desert-steppe and then to steppedesert (Shi and Shao, 2000; He et al., 2003; Liu et al., 2013).

\subsection{Soil sampling and data collection}

\subsubsection{Soil sampling}

To obtain accurate $K_{s}$ values, an intensive soil sampling scheme was designed, covering the entire typical Loess Plateau region. For more convenient access to the sampling sites, sampling routes were chosen along road transportation systems in the Loess Plateau. Every two adjacent sampling routes were about $40 \mathrm{~km}$ apart and the sites along the sampling route also about $40 \mathrm{~km}$ away from each other. For areas with more complex landscape and geomorphology, the sampling distance was reduced to include at least one randomly selected site for better representation of the area. Each sampling site was randomly selected and located using GPS receiver ( $5 \mathrm{~m}$ precision in the horizontal direction) to represent the main land use, soil type and topography within the range of vision. Sampling sites were selected at least $150 \mathrm{~m}$ away from the roads to reduce the effect of the road on conditions at the site (Fig. 1). Undisturbed soil cores were taken at each site at the 0-10 cm, 10-20 cm and 20-40 cm soil layer depths using metal cylinders ( $5 \mathrm{~cm}$ in diameter and $5 \mathrm{~cm}$ in length) to measure bulk density (BD), saturated soil water content (SSWC), field capacity (FC) and $K_{s}$. Disturbed soil samples were also collected at the corresponding soil depths to determine soil particle composition in the three layers.

Table 1

Descriptive statistics for soil hydraulic conductivity and other measured soil properties across the typical Loess Plateau $(\mathrm{n}=729)$.

\begin{tabular}{lccrrrrr}
\hline Variables & Minimum & Maximum & Mean & SD & CV & Skewness & Kurtosis \\
\hline$K_{s}(\mathrm{~mm} / \mathrm{min})$ & 0.01 & 0.99 & 0.37 & 0.25 & 67 & 0.69 & -0.21 \\
$\mathrm{BD}\left(\mathrm{g} / \mathrm{cm}^{3}\right)$ & 0.97 & 1.79 & 1.32 & 0.14 & 11 & 0.50 & 0.38 \\
$\mathrm{FC}(\%)$ & 0.04 & 0.38 & 0.19 & 0.04 & 25 & 0.02 & 0.61 \\
$\mathrm{SSWC}(\%)$ & 0.12 & 0.61 & 0.38 & 0.08 & 21 & -0.14 & 0.40 \\
$\mathrm{D}$ & 2.21 & 5.5 & 2.51 & 0.13 & 5 & 21.25 & 519.05 \\
Clay (\%) & 0.010 & 32.67 & 17.41 & 4.69 & 27 & -0.02 & -0.07 \\
Silt $(\%)$ & 2.04 & 76.01 & 63.33 & 9.85 & 16 & -2.49 & 8.54 \\
Sand $(\%)$ & 2.82 & 97.97 & 19.24 & 13.43 & 70 & 1.91 & 5.48 \\
Latitude $\left({ }^{\circ}\right)$ & 34.08 & 40.42 & 36.29 & 1.43 & 2 & 0.73 & -0.14 \\
Longitude $\left({ }^{\circ}\right)$ & 102.84 & 113.28 & 108.80 & 2.60 & 4 & -0.38 & -0.87 \\
\hline
\end{tabular}

SD standard deviation, CV coefficient of variation (\%) 
Table 2

Pearson's correlation coefficients between saturated hydraulic conductivity $\left(K_{s}\right)$ and their related factors in the typical Loess Plateau.

\begin{tabular}{|c|c|c|c|c|c|c|c|c|c|c|}
\hline Variable & Ks & $\mathrm{BD}$ & FC & SSWC & $\mathrm{D}$ & Clay & Silt & Sand & Latitude & Longitude \\
\hline$K_{s}$ & 1 & $-0.49^{* *}$ & 0.07 & $0.48^{* *}$ & 0.01 & $-0.09^{*}$ & $-0.10^{* *}$ & $0.08^{*}$ & $-0.12^{* *}$ & 0.03 \\
\hline $\mathrm{BD}$ & & 1 & $-0.26^{* *}$ & $-0.98^{* *}$ & 0.01 & -0.02 & $-0.23^{* *}$ & -0.05 & $0.32^{* *}$ & 0.07 \\
\hline FC & & & 1 & $0.28^{* *}$ & $0.27^{* *}$ & $0.59^{* *}$ & $0.57^{* *}$ & $-0.72^{* *}$ & $-0.23^{* *}$ & $-0.65^{* *}$ \\
\hline SSWC & & & & 1 & -0.01 & 0.02 & $0.25^{* *}$ & 0.041 & $-0.37^{* *}$ & $-0.09^{*}$ \\
\hline $\mathrm{D}$ & & & & & 1 & $0.27^{* *}$ & $0.23^{* *}$ & $-0.34^{* *}$ & $-0.11^{* *}$ & $-0.27^{* *}$ \\
\hline Clay & & & & & & 1 & $0.79^{* *}$ & $-0.70^{* *}$ & $-0.19^{* *}$ & $-0.55^{* *}$ \\
\hline Silt & & & & & & & 1 & $-0.65^{* *}$ & $-0.20^{* *}$ & $-0.58^{* *}$ \\
\hline Sand & & & & & & & & 1 & $0.19^{* *}$ & $0.79^{* *}$ \\
\hline Latitude & & & & & & & & & 1 & $0.35^{* *}$ \\
\hline Longitude & & & & & & & & & & 1 \\
\hline
\end{tabular}

Overall, the sample collection was done over a period of four months (June to October 2012) and the data were collected from a total of 729 undisturbed soil cores and disturbed soil samples for laboratory analysis.

\subsubsection{Laboratory analysis}

$K_{s}$ for the undisturbed soil cores was determined using the constant head method (Wang et al., 2013b). The soil cores were oven-dried at $105{ }^{\circ} \mathrm{C}$ for $48 \mathrm{~h}$, then weighed to calculate BD and SSWC (Wang et al., 2008a). The disturbed soil samples were air-dried and pass through $1.0 \mathrm{~mm}$ mesh to measure clay, silt and sand content (USDA taxonomy) using laser diffraction (Mastersizer 2000, Malvern Instruments, Malvern, England) (Liu et al., 2005). The longitudinal and latitudinal coordinates of each site were determined using GPS receiver. Then the fractal dimensions (D) were calculated based on the soil fractal model (Tyler and Wheatcraft, 1992).

\subsection{Data analysis}

\subsubsection{Pedotransfer function development}

For each soil layer (0-10, 10-20 and 20-40 cm), five soil properties (BD, D, Clay, Silt and Sand), two soil hydraulic parameters (FC and SSWC) and two geographical factors (longitude and latitude) were obtained to predict $K_{s}$. Standardization was done to limit the effect of dimension, variation and numerical magnitude of the variables on the data using the equation described by Jia et al. (2012). Finally, the 729 datasets were used to develop PTF using by both multiple linear regression (MLR) and artificial neural network (ANN) methods.

MLR is a traditional PTF development method with strong applicability that is a major branch of modern applied statistics. It has been widely used in soil science for developing PTF by predicting soil parameters (Parasuraman et al., 2006; Agyare et al., 2007; Motaghian and

Table 3

Root mean square error (RMSE), coefficient of determination $\left(\mathrm{R}^{2}\right)$ and the change proportion developed by MLR and ANN, respectively.

\begin{tabular}{|c|c|c|c|c|c|}
\hline \multirow[t]{2}{*}{ Model } & \multirow[t]{2}{*}{ Input variable } & \multicolumn{2}{|l|}{ Index } & \multicolumn{2}{|c|}{$\begin{array}{l}\text { Change } \\
\text { proportion (\%) }\end{array}$} \\
\hline & & RMSE & $\mathrm{R}^{2}$ & RMSE & $\mathrm{R}^{2}$ \\
\hline M1 & SSWC + Silt + Clay & 0.208 & 0.310 & - & - \\
\hline M2 & $\mathrm{BD}+$ Silt + Clay & 0.209 & 0.309 & -0.661 & 0.483 \\
\hline M3 & $\mathrm{BD}+$ Silt + Clay + SSWC & 0.210 & 0.307 & -0.765 & 0.918 \\
\hline M4 & BD + Silt + Clay + Sand & 0.209 & 0.307 & -0.659 & 0.921 \\
\hline M5 & $\mathrm{BD}+$ Silt + Clay + SSWC + Sand & 0.210 & 0.306 & -0.870 & 1.477 \\
\hline M6 & SSWC + Silt + Sand & 0.213 & 0.295 & -2.370 & 4.787 \\
\hline A1 & SSWC + Silt + Clay & 0.210 & 0.306 & - & - \\
\hline A2 & BD + Silt + Clay & 0.212 & 0.305 & -0.727 & 0.428 \\
\hline A3 & BD + Silt + Clay + Sand & 0.211 & 0.304 & -0.443 & 0.730 \\
\hline A4 & BD + Silt + Clay + SSWC + Sand & 0.212 & 0.303 & -0.728 & 0.942 \\
\hline A5 & $\mathrm{BD}+$ Silt + Clay & 0.212 & 0.297 & -0.897 & 2.901 \\
\hline A6 & SSWC + Silt + Sand & 0.213 & 0.297 & -1.444 & 2.943 \\
\hline
\end{tabular}

The hidden layers for A1, A2, A3, A4 and A6 have 1 layer and 4 neurons and that for A5 has 2 layer and 4 neurons.
Mohammadi, 2011). Recently, the ANN approach has been successfully used as a suitable data processing technique for modelling relationships between soil features and other measurable properties in PTF development (Pachepsky and Rawls, 1999; Baker and Ellison, 2008; Minasny and Mcbratney, 2000). ANN works similarly as the human brain and possesses similar functions of biological learning and memorization process. The feed-forward ANN model applied for this study consisted mainly of non-linear processing elements called simple neurons, which are organized into layers and interconnected as a network by weight. For ANN modelling, the number of hidden layers and the number of neurons in each hidden layer were designed via trial-and-error (Xiong et al., 2011). Initial values of the weights in each layer were assigned randomly and then determined by an error-correction learning rule. A pure linear function was selected for the output layer, while sigmoid activation function was assigned to the hidden layer.

The 729 dataset was randomly divided into two subsets, with subset-1 having 583 PTF developing records ( $80 \%$ of the total dataset) and subset- 2 having 146 validation records ( $20 \%$ of the total dataset). A total of 400 replicates of each subset were generated to limit error due to bias towards any particular calibration-validation dataset pairs and also to evaluate the stability of the PTF developed by different methods. The accuracy of the PTF was evaluated using the coefficient of determination $\left(\mathrm{R}^{2}\right)$ and the root mean square error (RMSE). Akaike's information criterion (AIC) was used to judge the superiority of the statistical model simulation results and the practicability of the models (Burnham and Anderson, 2004). The equations of $\mathrm{R}^{2}$, RMSE and AIC are documented by Wang et al. (2014) and Burnham and Anderson (2004).

\subsubsection{Used software}

The data were analysed using different software packages. The descriptive statistical parameters (mean, maximum, minimum, Skewness, Kurtosis and SD) and Pearson's correlation coefficients were determined using SPSS 14.0 (version) and coefficient of variance (CV) and AIC were calculated in Microsoft EXCEL (2013). MLR and ANN were measured using MATLAB (version R2009a), GIS software (ESRI ${ }^{\circledR}$ ArcMap $^{\text {TM }}$ 9.2) was used for maps and plots were designed in OriginPro (Version 9.2).

\section{Results and discussion}

\subsection{Descriptive statistics and $K_{s}$ factors}

\subsubsection{Descriptive statistics}

Descriptive statistics and overall variation in measured soil properties across the typical Loess Plateau region are shown in Table $1 . K_{s}$ varied within $0.01-0.99 \mathrm{~mm} / \mathrm{min}$ with a mean of $0.37 \mathrm{~mm} / \mathrm{min}$, a moderate variation of $67 \%$. The percent variation in BD, Silt, SSWC, FC, Clay and Sand was $11 \%, 16 \%, 21 \%, 25 \%, 27 \%$ and $70 \%$, respectively. While latitude, longitude and fractal dimension (D) had weak variations $-2 \%, 4 \%$ and 5 $\%$, respectively. 

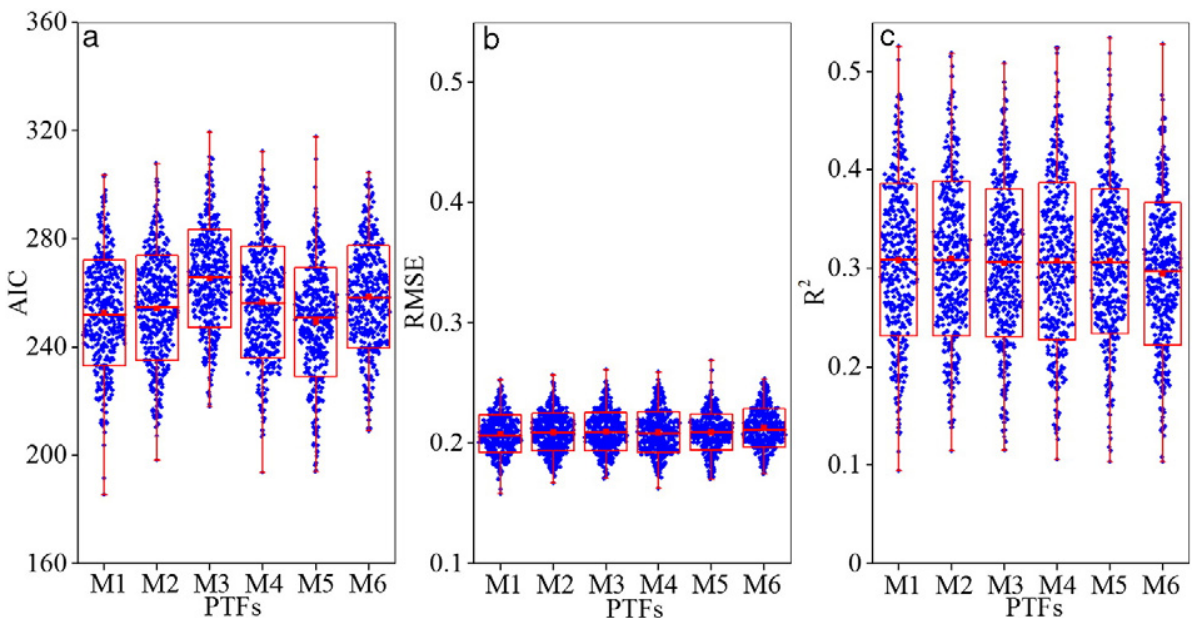

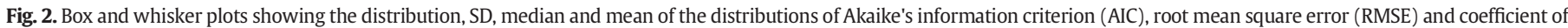
determination $\left(\mathrm{R}^{2}\right)$ of 400 times of validation for M1 to M6 model conditions.

BD had the least variation (11\%) among all the measured soil physical variables (11-70\%) while FC had the highest variation. This observation was in agreement with that by Wang et al. (2014) for the entire Loess Plateau region in China. The higher degree of variation in the parameters was possibly due to the differences in fluctuations in the data at small scale and large scale (Pachepsky et al., 2001; Zeleke and Bing, 2005). Based on the values for skewness and kurtosis in Table 1, $K_{s}$ and the other variables (e.g., BD, Clay, SSWC, FC, Silt and sand) were normally distributed, except $\mathrm{D}$.

\subsection{2. $K_{s}$ factors}

The degree of linear association of $K_{s}$ with other measured soil properties was determined using Pearson's correlation analysis (Table 2). $K_{s}$ was significantly correlated with 6 of the 9 measured variables - positively correlated with SSWC and Sand, while negatively correlated with BD, Clay, Silt and Latitude. However, BD, SSWC, Silt and Latitude had better correlation with $K_{S}(p<0.01)$ than Clay and Sand $(p<0.05)$. The correlation of $K_{s}$ with FC, D and Longitude was generally weak.

D is an important descriptive variable for soil particle distribution (Su et al., 2004). In this study, D was significantly correlated $(p<0.01$ ) with Clay, Silt and Sand. Then $K_{s}$ also had a significant correlation $(p<0.05)$ with Clay, Silt and Sand. Based on the correlation between $K_{s}$ and D, however, D was still not considered as a good parameter for the prediction of $K_{s}$ and could not be used in the place of Clay, Silt or Sand in developing PTF.

\subsection{Compartments of PTF}

\subsubsection{MLR/ANN-driven PTF}

In general, the performance of PTF varied with change of data used to develop and validate PTF. The 400 randomly selected datasets were used to minimize errors. Among the different combinations of the six factors, a stepwise process was conducted and the six best PTFs (relatively bigger $\mathrm{R}^{2}$ and smaller RMSE) developed by MLR and ANN selected. For ANN, the number of hidden layers and number of neurons were further optimised to have a good performance (Table 3). The performance of PTFs developed by MLR was better than that of PTFs developed by ANN. However, the difference in the two methods was not significant, as indicated by the percent change $(<5 \%)$ in RMSE and $\mathrm{R}^{2}$. The best $R^{2}$ value $(0.31)$ for all the PTFs was under M1 (combination of SSWC, Silt and Clay) model conditions (Table 3), the relatively small value mainly due to heterogeneity in $K_{s}$, soil texture, landscape and climatic conditions across the Loess Plateau (Wang et al., 2013b). Due to the insignificant difference in the accuracy of the simulation results, all the twelve PTFs could be used in predicting $K_{s}$ in the Loess Plateau of China. D due to the large size of the study area $\left(>6 \mathrm{~km}^{2}\right)$, direct measurements can be financially costly, and time and labour consuming. A
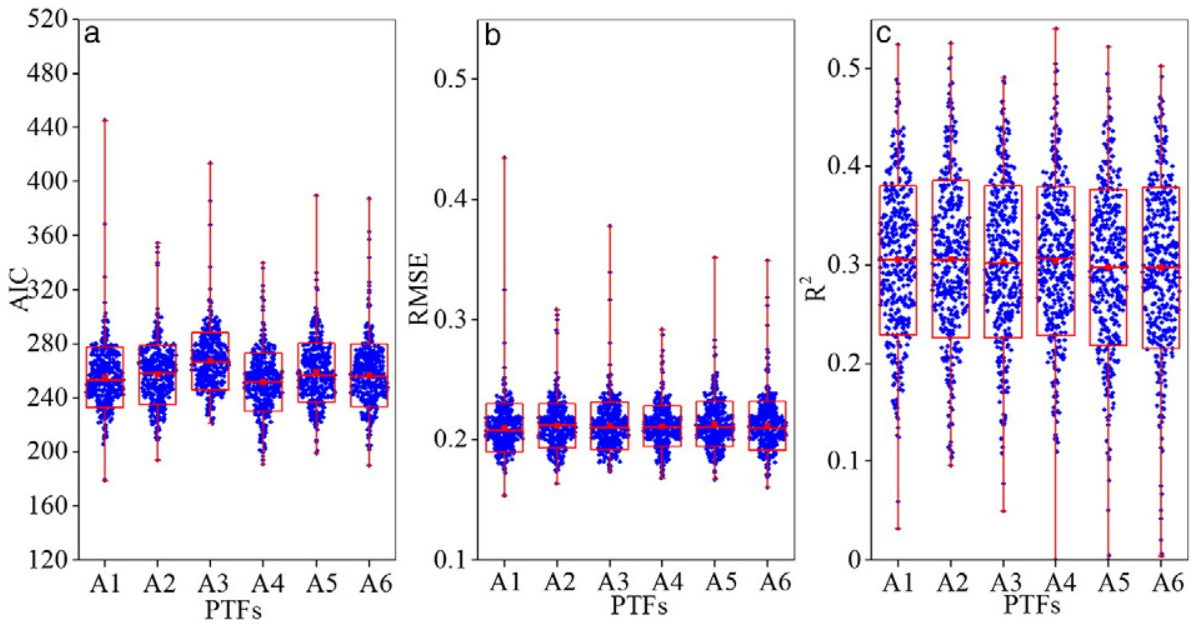

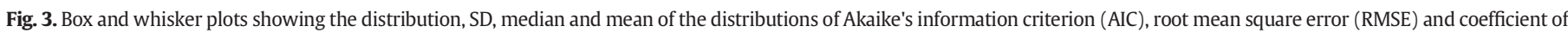
determination $\left(\mathrm{R}^{2}\right)$ of 400 times of validation for $\mathrm{A} 1$ to $\mathrm{A} 6$ model conditions. 
Table 4

Coefficients of the variables under M2-1 to M2-6 model conditions.

\begin{tabular}{lllll}
\hline Variable & $\mathrm{C}$ & BD & Silt & Clay \\
\hline M2-1 & 0.873 & -0.555 & -0.399 & 0.224 \\
M2-2 & 0.868 & -0.557 & -0.408 & 0.231 \\
M2-3 & 0.872 & -0.565 & -0.413 & 0.236 \\
M2-4 & 0.877 & -0.572 & -0.417 & 0.237 \\
M2-5 & 0.882 & -0.581 & -0.422 & 0.240 \\
M2-6 & 0.891 & -0.637 & -0.470 & 0.316 \\
\hline
\end{tabular}

" $\mathrm{C}$ " is a constant term of model.

PTF with a relatively low $\mathrm{R}^{2}$ is reliable for application in estimating soil water moment at large scale.

\subsubsection{MLR/ANN-driven PTF stability}

The stability of PTF performance has largely been overlooked in the previous studies (Agyare et al., 2007; Minasny and Mcbratney, 2000; Cornelis et al., 2001). The accuracy of PTF is not the only standard used to isolate the best PTF. Other factors such as PTF reliable and user-friendliness are also equally important. The stability of the performance, the number of variables and the ease of measurement of the variable should also take into account. Thus the distributions of AIC, RMSE and $\mathrm{R}^{2}$ (after repeating 400 times during development and validation) were calculated to isolate the best PTF for use in predicting $K_{s}$ in the Loess Plateau of China.

Based on the results, there were differences among the six MLRdriven PTFs, but not obvious in terms of range and SD of AIC, RMSE and $\mathrm{R}^{2}$ after 400 times of development and validation (Fig. 2). For ANN, however, the SDs of AIC, RMSE and $\mathrm{R}^{2}$ were similar and the ranges of AIC, RMSE and $\mathrm{R}^{2}$ obviously different for the PTFs. In short, the distributions of AIC (A2, A4), RMSE (A2, A4) and $R^{2}(A 2, A 3)$ were steadier than those of the other PTFs (Fig. 3a, b \& c). Generally, AIC, RMSE and $\mathrm{R}^{2}$ of PTF developed via MLR had smaller range than that developed via ANN (Figs. 2, 3a, b \& c). The unsteadiness, mainly shown in the wider ranges of AIC and RMSE, was bigger than the mean value, while that of $\mathrm{R}^{2}$ range was smaller than the mean value. The ranges between the best and mean value for AIC, RMSE and $\mathrm{R}^{2}$ were similar. Thus there was a high possibilities that the accuracies of A1, A3, A5 and A6 were lower than the average value. Although A2 and A4 distributions were better, they still failed to match with the stability of PTF developed via MLR. Subsequently, M2 was selected as the best PTF for: 1 ) relative steadiness of performance; 2 ) smallest number of variables and easiest value measurement; 3 ) analogous accuracy performance to M1.

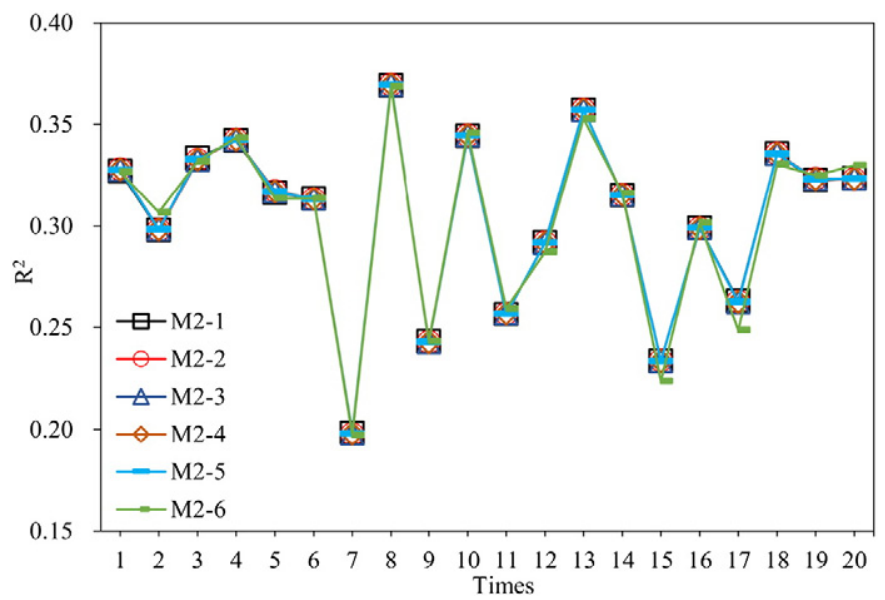

Fig. 5. Plot of the coefficient of determination $\left(R^{2}\right)$ of 20 randomly selected validations for M2-1 to M2-6 model conditions.

\subsection{Best PTF variable coefficients}

The coefficients of the variables varied with change in the data selected to develop PTF. A total of 400 times of random simulation with different coefficients were conducted to evaluate the stability of PTF through various combinations of BD, Silt and Clay. To find the best combination of coefficients, the 400 PTFs were realigned in a descending order of $\mathrm{R}^{2}$. The first and last PTF were selected as M2-1 and M2-6, respectively. The coefficients for the other variables in M2-2, M2-3, M24 and M2-5 were calculated use the mean values of the corresponding variables in the top $25 \%, 50 \%, 75 \%$ and $100 \%$ of the 400 PTFs (Table 4 ). A random selection of $20 \%$ of the 729 datasets was used to validate the six PTFs and the process repeated for 400 times.

After 400 times of validation run, there was no more obvious difference in the performance and stability of the six PTFs (Fig. 4a, b \& c). The ranges of AIC, RMSE and $\mathrm{R}^{2}$ as well as those of SD were similar for the six PTFs and also had similar means for the three indicators. The results suggested that the coefficient of any of the 400 PTF runs was good enough for to produce the best PTF result. Moreover, 20 of the 400 validations were randomly selected to check the performance of the six PTFs under the same validation data (Fig. 5). Although the performance changed significantly for different validation datasets, it was largely similar for the same validation dataset. It therefore concluded that the quality of PTF simulation result depended largely on the validation

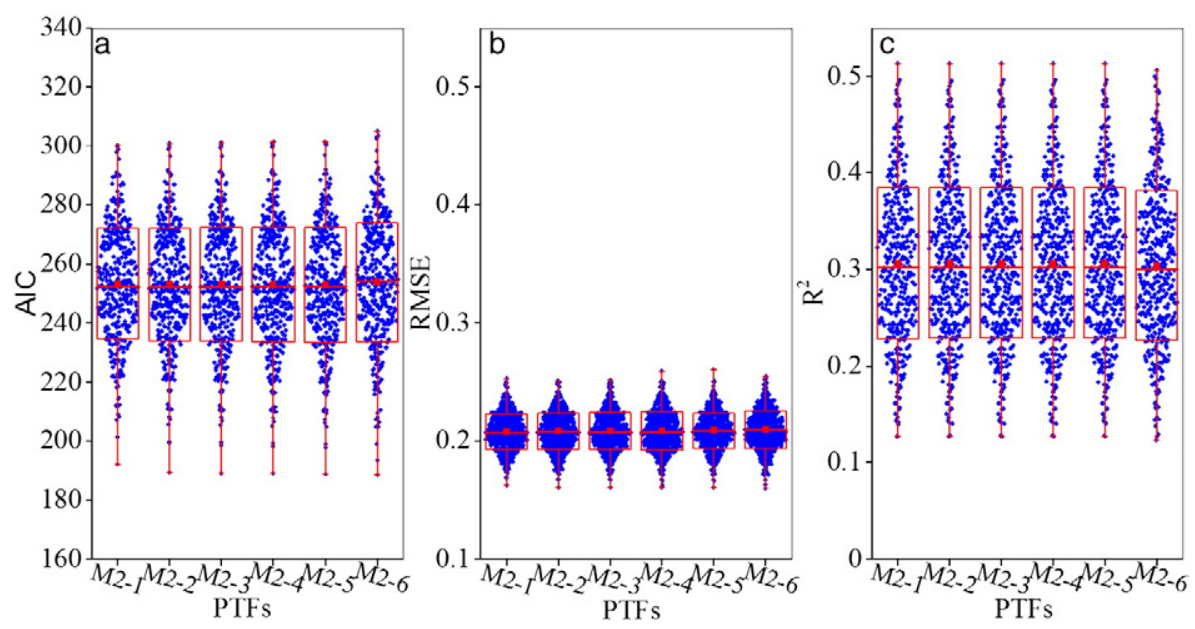

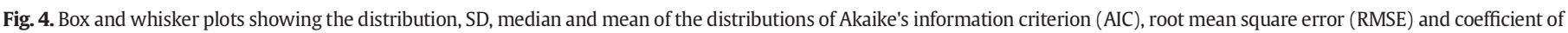
determination $\left(\mathrm{R}^{2}\right)$ of 400 times of validation for M2-1 to M2-6 model conditions. 
data used, which can be highly random. The different $\mathrm{R}^{2}$ values for the 400 PTFs were due mainly to the changes in validation datasets. To achieve a high estimation quality, it was important to repeatedly run validation analysis during the development of PTF.

\section{Conclusions}

In this study, 729 soil sample data were collected from 243 sites in the Loess Plateau and used developed PTF for the estimation of $K_{s}$ using two separate methods (MLR and ANN) and the results summarized as follows:

(1) Spatial variation in $K_{s}$ at regional scale was moderate (CV $\left.=67 \%\right)$. Correlation analysis showed that the primary factors driving regional distribution of $K_{s}$ were BD, SSWC, Clay, Silt and Latitude.

(2) A total of 400 times of development and validation showed that the performances of PTF developed by MLR and ANN were loosely similar. As the stability of PTF developed by ANN was weak, that developed by MLR method was preferred for application in developing PTF to estimate $K_{s}$. Soil bulk density, and silt and clay contents were also important for the estimation of $K_{s}$ in the Loess Plateau.

(3) As the randomness of the validation dataset had a significant effect on the indicators used to evaluate the quality of PTF, it was necessary to repeatedly validate PTF during the process of contrasting and selection.

\section{Acknowledgments}

This research was supported by the National Natural Science Foundation of China (41530854 and 41501233). Special thanks to the reviewers for the valuable suggestions on improving the standard of the paper.

\section{References}

Agyare, W.A., Park, S.J., Vlek, P.L.G., 2007. Artificial neural network estimation of saturated hydraulic conductivity. Vadose Zone J. 6, 423-431.

Aimrun, W., Amin, M.S.M., Eltaib, S.M., 2004. Effective porosity of paddy soils as an estimation of its saturated hydraulic conductivity. Geoderma 121, 197-203.

Baker, L., Ellison, D., 2008. Optimisation of pedotransfer functions using an artificial neural network ensemble method. Geoderma 144, 212-224.

Brantley, S.L., 2008. Understanding soil time. Science 321, 1454-1455.

Burnham, K.P., Anderson, D.R., 2004. Multimodel Inference Understanding AIC and BIC in model selection. Sociol. Methods Res. 33, 261-304.

Chapuis, R.P., 2012. Predicting the saturated hydraulic conductivity of soils: a review. Bull. Eng. Geol. Environ. 71, 401-434.

Chen, L.D., Wei, W., Fu, B.J., Lu, Y.H., 2007. Soil and water conservation on the Loess Plateau in China: review and perspective. Prog. Phys. Geogr. 31, 389-403.

Cornelis, W.M., Ronsyn, J., Van Meirvenne, M., Hartmann, R., 2001. Evaluation of pedotransfer functions for predicting the soil moisture retention curve. Soil Sci. Soc. Am. J. 65, 638-648.

Cosby, B.J., Hornberger, G.M., Clapp, R.B., Ginn, T.R., 1984. A statistical exploration of the relationships of soil moisture characteristics to the physical properties of soils. Water Resour. Res. 20, 682-690.

Duan, R., Fedler, C.B., Borrelli, J., 2012. Comparison of methods to estimate saturated hydraulic conductivity in Texas soils with grass. J. Irrig. Drain. E-Asce 138, 322-327.

He, X., Li, Z., Hao, M., Tang, K., Zheng, F., 2003. Down-scale analysis for water scarcity in response to soil-water conservation on Loess Plateau of China. Agric. Ecosyst. Environ. 94, 355-361.

Hu, W., Shao, M.A., Si, B.C., 2012. Seasonal changes in surface bulk density and saturated hydraulic conductivity of natural landscapes. Eur. J. Soil Sci. 63, 820-830.

Jia, X., Shao, M.A., Wei, X., 2012. State-space prediction of soil respiration time series in temperate, semi-arid grassland in northern China. Soil Res. 50, 293-303.

Jia, X., Shao, M.A., Zhang, C., Zhao, C., 2015. Regional temporal persistence of dried soil layer along south-north transect of the Loess Plateau, China. J. Hydrol. 528, 152-160.

Lei, G., Shao, M., Wang, Y., 2012. Spatial scaling of saturated hydraulic conductivity of soils in a small watershed on the Loess Plateau, China. J. Soils Sediments 12, 863-875.
Lilly, A., Nemes, A., Rawls, W.J., Pachepsky, Y.A., 2008. Probabilistic approach to the identification of input variables to estimate hydraulic conductivity. Soil Sci. Soc. Am. J. 72 $16-24$.

Liu, Y.P., Tong, J., Li, X.N., 2005. Analysing the silt particles with the Malvern Mastersizer 2000. Water Conserve. Sci. Tech. Econ. 11, 329-331 (in Chinese with English abstract).

Liu, Z.P., Shao, M.A., Wang, Y.Q., 2013. Spatial patterns of soil total nitrogen and soil total phosphorus across the entire Loess Plateau region of China. Geoderma 197-198, 67-78.

Mcbratney, A.B., Minasny, B., Cattle, S.R., Vervoort, R.W., 2002. From pedotransfer functions to soil inference systems. Geoderma 109, 41-73.

Minasny, B., Mcbratney, A.B., 2000. Evaluation and development of hydraulic conductivity pedotransfer functions for Australian soil. J. Soil Res. 38, 905-926.

Motaghian, H.R., Mohammadi, J., 2011. Spatial estimation of saturated hydraulic conductivity from terrain attributes using regression, kriging, and artificial neural networks. Pedosphere 21, 170-177.

Nepstad, D.C., Decarvalho, C.R., Davidson, E.A., Jipp, P.H., Lefebvre, P.A., Negreiros, G.H. Dasilva, E.D., Stone, T.A., Trumbore, S.E., Vieira, S., 1994. The role of deep roots in the hydrological and carbon cycles of Amazonian forests and pastures. Nature 372, 666-669.

Pachepsky, Y.A., Rawls, W.J., 1999. Accuracy and reliability of pedotransfer functions as affected by grouping soils. Soil Sci. Soc. Am. J. 63, 1748-1757.

Pachepsky, Y.A., Timlin, D.J., Rawls, W.J., 2001. Soil water retention as related to topographic variables. Soil Sci. Soc. Am. J. 65, 1787-1795.

Parasuraman, K., Elshorbagy, A., Si, B.C., 2006. Estimating saturated hydraulic conductivity in spatially variable fields using neural network ensembles. Soil Sci. Soc. Am. J. 70, 1851-1859.

Rawls, W.J., Brakensiek, D.L., Logsdon, S.D., 1993. Predicting saturated hydraulic conductivity utilizing fractal principles. Soil Sci. Soc. Am. J. 57, 1193-1197.

Robinson, N., Harper, R.J., Smettem, K.R.J., 2006. Soil water depletion by Eucalyptus spp. Integrated into dryland agricultural systems. Plant Soil 286, 141-151.

Saxton, K.E., Rawls, W.J., 2006. Soil water characteristic estimates by texture and organic matter for hydrologic solutions. Soil Sci. Soc. Am. J. 70, 1569-1578.

Saxton, K.E., Rawls, W.J., Romberger, J.S., Papendick, R.I., 1986. Estimating generalized soil-water characteristics from texture. Soil Sci. Soc. Am. J. 50 (NP-NP).

Shi, H., Shao, M., 2000. Soil and water loss from the Loess Plateau in China. J. Arid Environ. $45,9-20$.

Su, Y.Z., Zhao, H.L., Zhao, W.Z., Zhang, T.H., 2004. Fractal features of soil particle size distribution and the implication for indicating desertification. Geoderma 122, 43-49.

Tyler, S.W., Wheatcraft, S.W., 1992. Fractal scaling of soil particle-size distributions: analysis and limitations. Soil Sci. Soc. Am. J. 56, 362-369.

Vereecken, H., Weynants, M., Javaux, M., Pachepsky, Y., Schaap, M.G., Van Genuchten, M.T., 2010. Using pedotransfer functions to estimate the Van Genuchten-Mualem soil hydraulic properties: a review. Vadose Zone J. 9, 795-820.

Vos, B.D., Meirvenne, M.V., Quataert, P., Deckers, J., Muys, B., 2005. Predictive quality of pedotransfer functions for estimating bulk density of forest soils. Soil Sci. Soc. Am. J. 69, 500-510.

Wang, D., Fu, B., Zhao, W., Hu, H., Wang, Y., 2008a. Multifractal characteristics of soil particle size distribution under different land-use types on the Loess Plateau, China. Catena 72, 29-36.

Wang, L., Wang, Q., Wei, S., Shao, M.A., Li, Y., 2008b. Soil desiccation for Loess soils on natural and regrown areas. For. Ecol. Manag. 255, 2467-2477.

Wang, Y., Shao, M.A., Liu, Z., 2013a. Vertical distribution and influencing factors of soil water content within 21-m profile on the Chinese Loess Plateau. Geoderma 193-194, 300-310.

Wang, Y., Shao, M.A., Liu, Z., Horton, R., 2013b. Regional-scale variation and distribution patterns of soil saturated hydraulic conductivities in surface and subsurface layers in the loessial soils of China. J. Hydrol. 487, 13-23.

Wang, Y., Shao, M.A., Liu, Z., Zhang, C., 2014. Prediction of bulk density of soils in the Loess Plateau region of China. Surv. Geophys. 35, 395-413.

Wösten, J.H.M., Lilly, A., Nemes, A., Bas, C.L., 1999. Development and use of a database of hydraulic properties of European soils. Geoderma 90, 169-185.

Wösten, J.H.M., Pachepsky, Y.A., Rawls, W.J., 2001. Pedotransfer functions: bridging the gap between available basic soil data and missing soil hydraulic characteristics. J. Hydrol. 251, 123-150.

Xiong, Y., Wallach, R., Furman, A., 2011. Modeling multidimensional flow in wettable and water-repellent soils using artificial neural networks. J. Hydrol. 410, 92-104.

Yang, Q.Y., Zhang, B.P., Zheng, D., 1988. On the boundary of the Loess Plateau. J. Nat. Resour. 3, 9-15 (in Chinese with English abstract).

Yao, R.J., Yang, J.S., Wu, D.H., Li, F.R., Gao, P., Wang, X.P., 2015. Evaluation of pedo-transfer functions for estimating saturated hydraulic conductivity in coastal salt-affected mud farmland. J. Soils Sediments 15, 902-916.

Zeleke, T.B., Bing, C.S., 2005. Scaling relationships between saturated hydraulic conductivity and soil physical properties. Soil Sci. Soc. Am. J. 69, 1691-1702.

Zhao, C., Shao, M., Jia, X., 2014. Distribution and simulation of saturated soil hydraulic conductivity at a slope of northern Loess Plateau. Adv. Water Sci. 25, 806-815 (in Chinese with English abstract).

Zhou, B.B., Shao, M.A., Shao, H.B., 2009. Effects of rock fragments on water movement and solute transport in a Loess Plateau soil. Compt. Rendus Geosci. 341, 462-472. 